\title{
A RELEVÂNCIA DA CONTABILIDADE PARA A GESTÃO DO MICROEMPREENDEDOR INDIVIDUAL
}

\section{ARTIGO ORIGINAL}

SOUZA, Beatriz Oliveira de ${ }^{1}$, SILVA, Matheus Souza da ${ }^{2}$, SILVA, Brenda Magalhães da $^{3}$, SÁ, Ana Paula Silva ${ }^{4}$, ROBERTO, José Carlos Alves ${ }^{5}$, SERRA, Meg Rocha da Cunha $^{6}$, LOPES, Nelânia Ferreira ${ }^{7}$

SOUZA, Beatriz Oliveira de. Et al. A relevância da contabilidade para a gestão do microempreendedor individual. Revista Científica Multidisciplinar Núcleo do Conhecimento. Ano. 06, Ed. 11, Vol. 04, pp. 98-123. Novembro 2021. ISSN: 24480959, Link de

acesso: $\quad$ https://www.nucleodoconhecimento.com.br/contabilidade/gestao-domicroempreendedor, DOI: 10.32749/nucleodoconhecimento.com.br/contabilidade/gestao-domicroempreendedor

\section{RESUMO}

Com o objetivo de trazer a visão da importância da contabilidade e do profissional contábil para o controle e crescimento do Microempreendedor Individual (MEI), este artigo visa responder o seguinte questionamento: Como o profissional contábil pode contribuir para o controle e organização de um MEl? A metodologia aplicada neste trabalho corresponde ao método explicativo qualitativo, realizado através do uso de

\footnotetext{
${ }^{1}$ Graduando do curso de Contabilidade.

${ }^{2}$ Graduando do curso de Contabilidade.

${ }^{3}$ Graduando do curso de contabilidade.

${ }^{4}$ Graduando do curso de contabilidade.

${ }^{5}$ Orientador. Mestre em Engenharia de produção. Especialista Logística empresarial. Graduado em Administração com Ênfase em Marketing.

${ }^{6}$ Orientadora. Mestra em Engenharia de Processos Industriais pela UFPA, especialista em Controladoria e Auditoria Contábil pelo Ciesa, Graduada em Ciências Contábeis pelo Centro Universitário do Norte. Graduada em Ciências Econômicas pelo Centro Universitário do Norte.

${ }^{7}$ Orientadora. Especialista em Auditoria Contábil, Financeira e Tributaria e Graduada em Ciências Contábeis.
} 
fontes primárias e secundárias, seja por artigos, livros e websites, além de pesquisas bibliográficas de autores e estudiosos da contabilidade. Em virtude das tratativas abordadas neste trabalho, é visto a importância da presença da contabilidade com auxílio do contador no $\mathrm{MEI}$, tendo em vista a exorbitante falta de conhecimento contábil por parte dessa classe de empreendedores. Deste modo, a Contabilidade, através do auxílio do profissional contábil, utiliza-se das ferramentas contábeis gerenciais, tais como: balanço patrimonial, Demonstrativo do Resultado do exercício (DRE) e fluxo de caixa. Ferramentas estas que possibilitam a melhoria da gestão empresarial, contribuindo para a melhora na tomada de decisões, controle de custos e despesas, controles bancários e, consequentemente, a alavancagem financeira da empresa.

Palavras-chave: Microempreendedor Individual, Contabilidade, Profissional contábil, Ferramentas contábeis, Contabilidade gerencial.

\section{INTRODUÇÃO}

Este artigo discutirá os benefícios que os contadores podem trazer para o aperfeiçoamento do microempreendedor individual por meio de uma bibliografia. Trata-se de um projeto do governo federal que visa reduzir o índice informal de empresários por meio da promulgação da lei complementar 128, em 2008. Esta refere-se às pessoas físicas Microempreendedores - a criação da MEI. No entanto, muitas pessoas optam por conduzir negócios sem a supervisão de profissionais de contabilidade, o que pode criar obstáculos para a gestão e o crescimento futuro dos negócios.

Para Vergara (2016), problema é o que vai nortear a pesquisa de um artigo, tornando-se uma pergunta para ser respondida, sendo assim, é por meio da pergunta problema que o autor irá basear suas pesquisas e objetivos. À vista disso, o presente artigo busca responder o seguinte questionamento: Como o profissional contábil pode contribuir para o controle e organização de um MEI? 
Como método, foi realizada uma revisão de literatura. Para Vergara (2016), trata-se de um estudo de livros e artigos que servem de base para novas ideias.

Chupel et al. (2014) afirmam que a contabilidade está se tornando cada vez mais comum como meio de auxílio à gestão e à tomada de decisão. Para Ribeiro e Dos Santos (2018), a contabilidade gerencial é utilizada para interpretar os dados contábeis e gerar informações que podem ser utilizadas para a tomada de decisão e gestão da empresa.

Espera-se, portanto, com esta pesquisa, fornecer aos usuários e interessados em gestão, informações que possam gerar interesse e conhecimento, principalmente àqueles microempreendedores individuais que evitam 0 hábito de serem acompanhados por especialistas da área. A pesquisa será conduzida para aumentar a credibilidade dos profissionais de contabilidade nas funções de gestão de negócios por meio de seus conhecimentos específicos na área.

\section{FUNDAMENTAÇÃO TEÓRICA}

Para Azevedo (2016), quando se faz uma pesquisa, o autor precisa de base teórica para a construção do seu texto. Essa base se dá por meio de artigos, livros e outros autores que possam disponibilizar ao escritor ideias relacionadas a sua pesquisa, trazendo veracidade científica a seu trabalho.

Portanto, nesse tópico, o autor do trabalho traz ideias e assuntos coerentes à sua pesquisa que, neste caso, sendo uma revisão de literatura, visa contribuir com as publicações existentes.

\subsection{MICROEMPREENDEDOR INDIVIDUAL (MEI)}

O Microempreendedor Individual (MEI) surgiu através da Lei Complementar 128/2008. Para Andrade e França (2020), foi uma forma do governo diminuir a informalidade dos empreendedores, garantindo a eles benefícios e vantagens, e, ao país, um desenvolvimento econômico. 
Conforme o SEBRAE (2021), todo profissional autônomo que quer sair da informalidade, passando a ter CNPJ, se denomina MEI - Microempreendedor Individual. Este recebe algumas vantagens como empréstimos com juros mais baixos, emissão de notas ou aposentadoria e deve auferir um faturamento de $R \$$ $81.000,00$ anual e $\mathrm{R} \$ 6.750,00$ mensal, podendo ter outra empresa como titular ou sócio.

Segundo Mesquita (2016), a criação do projeto do MEl se deu por causa da existência de muita burocracia para a constituição de um CNPJ e da elevada carga tributária que corroboraram para que os empreendimentos continuassem na informalidade. Assim, para resolver tais problemas foi elaborado este projeto com uma tributação simples e de fácil abertura, fazendo com que a informalidade diminuísse.

O MEI deve pagar suas obrigações através do Documento de Arrecadação (DAS), onde consta sua contribuição previdenciária como, $R \$ 1,00$ de ICMS, caso seja contribuinte e $\mathrm{R} \$ 5,00$ de ISS, caso seja contribuinte. O microempreendedor ficará isento de IRPJ, CSLL, PIS/PASEP, caso não trabalhe com importação; Contribuição previdenciária patronal, a não ser que contrate um funcionário, lembrando que o $\mathrm{MEI}$ pode ter apenas um funcionário; entre outros. O empreendedor também deve manter o relatório de receita mensal e de receitas brutas, e apresentar a Declaração Anual para o MEI - DASN-SIMEI (SIMPLES NACIONAL, 2021).

Portanto, sabe-se que a gênese do microempreendedor se deu pela necessidade de - governo tirar da informalidade todos os empreendedores, facilitar sua administração e, ainda, desenvolver sua economia.

\subsubsection{BENEFÍCIOS DO MICROEMPREENDEDOR INDIVIDUAL}

Segundo o portal do SEBRAE (2021), sendo MEl o empreendedor, este se enquadra no regime do Simples Nacional, ficando isento dos tributos federais e pode ter remuneração por afastamento relacionado a problemas de saúde, além de apoio 
técnico pelo próprio site do Sebrae, onde pode obter ensino de gestão, possibilitando uma melhor noção de gerenciamento e de mercado, entre outros benefícios. Conforme Mesquita (2016), um dos benefícios do MEl é de poder se aposentar por idade ou por tempo de contribuição, sendo que, pela última opção, ele deverá contribuir com $5 \%$ e, para que seja completa, deverá contribuir com $20 \%$, pagando, portanto, os $15 \%$ de diferença. Ademais, ele também poderá contar com salário maternidade, pensão por morte, entre outros.

Para Chupel et al. (2014), além de o microempreendedor ter sua carga tributária diminuída e isenção em taxas para o registro da empresa, o MEI também garante auxílio do SEBRAE e serviços contábeis gratuitos que podem facilitar ainda mais o seu gerenciamento e a abertura de contas e empréstimos bancários.

Para Da Silva (2014) outro benefício que está relacionado ao negócio, é o da emissão de notas e comprovação de renda. Este facilita a realização de empréstimos com juros baixos pelo microempreendedor por ter CNPJ, possibilitando a extensão do seu empreendimento, a fim de que possa se desenvolver e criar novidades no mercado.

A abertura do CNPJ garante não só aposentadoria, mas o auxílio saúde e doença, como também possíveis financiamentos para alavancar o desenvolvimento do seu negócio, já que os juros são baixos.

\subsection{CONCEITO DE CONTABILIDADE}

Para Ribeiro (2013), somente a contabilidade concede ao empreendedor o conhecimento real de seu Patrimônio, que por meio de seus demonstrativos expõem a saúde econômico-financeira da instituição. Os usuários são os que utilizam esses demonstrativos para tomar conhecimento do seu negócio e controlar a gestão da mesma. Além do mais, Rodrigues (2021) complementa que, devido à falta de noção e entendimento quanto à organização e gestão dos recursos, o ser humano entendeu que precisava controlar e administrar seus bens e, através dessa 
necessidade, teve-se o surgimento da contabilidade, para cumprir este papel fundamental na sociedade. Ou seja, a ciências contábeis surgiu sob a função social de cuidar do patrimônio do ser humano.

Os estudos de Chupel et al. (2014) nos revelam que o uso da contabilidade vem aumentando com o passar do tempo e que sua utilização se dá pelo fato de promover uma melhor gestão e tomada de decisão, o que, para ele, é justamente a função desta ciência. Segundo o autor, é possível realizar o controle do Patrimônio da empresa por meio da contabilização das informações geradas pela mesma, permitindo que ela evolua e cumpra seus objetivos e metas.

Lames (2019), por sua vez, afirma que há várias interpretações quanto ao conceito de contabilidade, não havendo uma unanimidade quanto a esse tema. $O$ consenso que há entre os principais autores é de que a contabilidade está relacionada ao patrimônio. Portanto, quando se fala de contabilidade, o que se pode pensar é que é uma ciência que estuda o patrimônio dividido em bens, direitos e obrigações.

Desta forma, entende-se que a contabilidade observa o patrimônio das empresas e pode ser dividida em áreas que podem trazer às entidades benefícios quanto ao seu controle e organização.

\subsubsection{CONTABILIDADE X MICROEMPREENDEDOR INDIVIDUAL}

Para Costa e Feitosa Filho (2019), um dos fatores que servem como argumento para a não utilização da contabilidade é a não obrigatoriedade da escrituração dos livros fiscais. As ciências contábeis não dizem respeito somente à escrituração ou à tributação como muitos pensam, pois é por meio da contabilidade que se pode montar estratégias gerenciais com o intuito de potencializar o progresso do negócio. Desta forma, para o MEl é de total interesse controlar e organizar seu faturamento de $R \$ 81.000,00$ anual e de $R \$ 6.750,00$ mensal para que esse valor não extrapole e o obrigue a se desenquadrar. 
Quanto a utilização da contabilidade pelo microempreendedor individual, Araujo e Dos Santos (2019) dizem que é uma ferramenta muito eficiente para que o gestor possa tomar decisões corretas. Porém, devido a ignorância do empreendedor, ela só é utilizada com o propósito de controlar a sua tributação fiscal, não conhecendo o fator organizacional dessa ciência, o que reflete na pouca procura da contabilidade para o controle e o auxílio no julgamento correto das ações.

Ainda quanto à utilização do contador, Chupel et al. (2014) confirmam que esta geralmente é utilizada apenas para o acompanhamento fiscal, o que é ruim não apenas para o profissional contábil, mas para o negócio, tendo em vista a capacidade da contabilidade de oferecer ao empreendedor mais segurança na escolha de seus passos, diminuindo as possibilidades de erros futuros.

Outro passo importante para que uma empresa consiga se desenvolver é a formação do preço de vendas. Para Andrade e França (2020), um dos motivos para que uma entidade obtenha lucro é a formação do preço de vendas. Segundo eles, é importante ter conhecimento sobre os seus produtos e o quanto eles podem trazer de benefícios ou prejuízos para a sua empresa, tendo base para tomar a decisão correta quanto a permanência desse produto no seu negócio.

Sendo assim, a contabilidade pode ser vista como uma aliada do empreendedor quanto a apresentação de ferramentas de controle, organização e tomada de decisão. Não ficando presa apenas em apuração de lucro ou de recolhimento fiscal.

\subsection{CONTABILIDADE COMO FERRAMENTA DE GESTÃO}

Para Costa e Feitosa Filho (2019), o foco de uma pessoa quando abre um negócio é lucrar,o que demanda a busca por ferramentas e meios para conseguir obter êxito com seu negócio. A partir dessa ideia, pela lógica, o mesmo deveria buscar na contabilidade tais ferramentas, visto que, por meio de demonstrativos ela entrega ao empreendedor informações úteis, a fim de traçar planos e objetivos para desenvolver seu empreendimento. 
Martins (2018) afirma que a contabilidade oferece instrumentos que podem ajudar na interpretação das informações geradas pela entidade no seu exercício diário para servirem de base para a tomada de decisões da empresa. Controle de orçamento, análise das evidências contábeis, cálculos de custo de produtos e definição de preço de vendas são alguns desses instrumentos.

Além disso, Rodrigues (2021) vê a contabilidade como uma intérprete de dados que objetiva desenvolver demonstrativos para a empresa, a fim de expor a realidade financeira da mesma. A contabilidade deve selecionar as melhores informações para que possa realizar uma boa avaliação da organização e, assim, usar essa inspeção para produzir um bom diagnóstico.

Conforme a concepção de Alencar e Dias (2018), o mercado atual está mais adverso e difícil de se firmar, onde apenas os melhores se destacam. Tendo em vista este problema, o contador é a saída para que o empreendedor possa planejar e criar estratégias como forma de gerir seu negócio. Sendo necessário a colaboração de todos que trabalham no negócio com o objetivo de obter êxito nos objetivos e metas.

Infere-se então que a contabilidade oferece ao negócio possibilidade de crescimento no mercado, tendo em vista que na atualidade somente os melhores conseguem sucesso e o profissional contábil pode ajudá-lo a obter êxito em seus objetivos.

\subsubsection{FERRAMENTAS CONTÁBEIS}

Do Carmo (2017) afirma que a análise contábil entrega ao empreendedor informações sobre a saúde financeiro-econômica do patrimônio da empresa. Tais dados serão melhores aproveitados através de um especialista contábil, pois, o mesmo possui conhecimento específico para que essas informações possam ser compreendidas e apresentadas de forma mais clara ao empreendedor.

Rocha et al. (2018) afirmam que para haver segurança nas decisões e evitar ocorrências negativas no futuro, os administradores devem tomar suas deliberações 
através de relatórios contábeis, sendo estes desenvolvidos pelo contador com informações relevantes para que as decisões sejam eficientes.

Conforme os dados de Assis et al. (2017), os administradores vêem os serviços de contabilidade necessários apenas quando querem saber da sua realidade financeira, quando precisam de alguma informação relacionada ao fisco ou quando querem esclarecimentos quanto aos procedimentos legais em relação aos seus empregados.

Uma boa ferramenta é o exame das demonstrações contábeis que, para Nascimento (2015), são relatórios contábeis realizados com as informações de um certo período. Essas demonstrações, algumas até obrigatórias como é o caso do Balanço Patrimonial e da Demonstração de Resultado do Exercício (DRE), além de apresentarem a situação econômico-financeiro da entidade, auxiliam o gestor a tomar as melhores decisões quanto aos passos futuros da empresa.

Logo, através das ferramentas contábeis, pode-se não somente analisar a capacidade financeira do estabelecimento, mas também traçar medidas que possam melhorar a situação da entidade.

\subsubsection{BALANÇO PATRIMONIAL}

Ribeiro (2013) define Balanço Patrimonial como um relatório quantitativo e qualitativo do patrimônio. Resume-se em Ativo circulante e não circulante, que classifica as contas por grau de liquidez (capacidade em que uma determinada conta gera dinheiro), sendo que, as contas do circulante têm um grau de liquidez maior e o não circulante menor, e Passivo circulante e não circulante, onde as contas são classificadas em grau de exigibilidade (necessidade de quitação de uma determinada obrigação), em que as contas do circulante tem um grau maior do que as contas do não circulante.

Para Alencar e Dias (2018), o balanço patrimonial é uma ótima ferramenta para a tomada de decisão de um gestor, visto que, por meio deste demonstrativo pode-se

RC: 100797

Disponível em: https://www.nucleodoconhecimento.com.br/contabilidade/gestao-domicroempreendedor 
montar outros relatórios financeiros. O balanço evidencia a saúde econômicofinanceira de um período social de uma entidade. Já para Do Carmo (2017), o balanço é o principal relatório contábil, pois, através dele se conhece a real situação patrimonial em um dado período. Para ele, todas informações relevantes são divulgadas por meio desse demonstrativo.

Conforme o pensamento de Martins et al. (2014), o balanço patrimonial demonstra a saúde patrimonial e financeira de forma visual como se fosse uma "foto" dessa situação da empresa. Portanto, é um diagnóstico de como a entidade está depois de todo o exercício anual, sendo uma bússola para o gesto guiar-se quando for tomar alguma decisão.

Diante disso, o balanço pode oferecer ao empreendedor materiais que auxiliem no processo decisório do negócio, assim como, avaliar a situação econômico-financeira da mesma. O quadro abaixo representa de maneira simplificada o balanço patrimonial.

Tabela 1 - Balanço Patrimonial

Balanço Patrimonial

\begin{tabular}{lclr|}
\hline Ativo & & Passivo & \\
Circulante & $27.352,00$ & Circulante & $\mathbf{1 4 . 1 7 8 , 0 0}$ \\
\hline Caixa & $\mathbf{4 . 5 0 0 , 0 0}$ & Fornecedores & $5.778,00$ \\
\hline Banco Conta Movimento & $\mathbf{5 . 2 2 0 , 0 0}$ & Salários a pagar & $2.200,00$
\end{tabular}

\begin{tabular}{|lrll|}
\hline Clientes & $\mathbf{1 0 . 4 3 2 , 0 0}$ & Contas a pagar & \multicolumn{1}{l}{$6.200,00$} \\
\hline Estoque & $\mathbf{7 . 2 0 0 , 0 0}$ & Não Circulante & $\mathbf{1 5 . 0 0 0 , 0 0}$ \\
\hline Não Circulante & $23.930,00$ & Empréstimos e financiamentos 15.000,00 \\
\hline Imobilizado & $\mathbf{1 5 . 7 0 0 , 0 0}$ & Patrimônio Líquido & \\
\hline Investimentos & $\mathbf{5 . 1 1 0 , 0 0}$ & Capital Social & $20.000,00$
\end{tabular}




\section{Intangível}

Total
$3.120,00$

$51.282,00$
Lucros ou Prejuízos acumulado 2.104,00

Total
$51.282,00$

Fonte: Própria (2021)

\subsubsection{DEMONSTRAÇÃO DO RESULTADO DO EXERCÍCIO}

Conforme Ribeiro (2013), é no demonstrativo do resultado que o empresário saberá se durante seu exercício anual obteve ganho ou prejuízo. Nesse demonstrativo estão reunidos todos os gastos e receitas de um dado momento. Portanto, com esse relatório a entidade poderá ter a ciência de como está sua situação, observando se há a necessidade de mudar suas estratégias ou não, a fim de alcançar os objetivos definidos para a empresa.

Conforme os estudos de Gonçalves et al. (2019), este demonstrativo permite que a entidade tenha crédito no mercado, pois, esse relatório relata se o saldo financeiro da empresa é positivo ou se o investimento pode ser arriscado, como no caso de saldo negativo. Porém, muitos usuários confundem lucro com liquidez de caixa, que é dinheiro disponível, e assim acabam deixando a DRE de lado, por haver a incompreensão de que para uma entidade estar bem financeiramente ela deve ter dinheiro em caixa, o que é por lógica o inverso.

Em seguida, Costa et al. (2016) complementam que, através da demonstração do resultado, a entidade pode avaliar como estão os processos de decisão da empresa, se estão dando frutos ou não, e então montar um novo planejamento financeiro a fim de reverter uma situação negativa ou uma nova estratégia com o intuito de desenvolver ainda mais o negócio.

Martins et al. (2014) explicam essa demonstração como sendo a diferença entre as receitas e as despesas no espaço de tempo que estes dados foram extraídos, onde as receitas são os resultados positivos do aumento do ativo ou diminuição do passivo no período e as despesas são os resultados da diminuição do ativo e 
aumento do passivo, não sendo um resultado negativo em si, pois essas despesas podem trazer frutos positivos no futuro.

Portanto, é esta demonstração que apura os rendimentos de uma empresa, sendo muito confundido erroneamente com a demonstração do fluxo de caixa. Abaixo temse um quadro com uma DRE simplificada.

Tabela 2 - Demonstração do Resultado do Exercício

\begin{tabular}{|c|c|}
\hline $\begin{array}{l}\text { Demonstração do Resultado do } \\
\text { Exercício }\end{array}$ & $\mathbf{R} \$$ \\
\hline Receita Operacional & $16.220,00$ \\
\hline (-) Devoluções e Descontos Cedidos & $(-1.240,00)$ \\
\hline (=) Receita Líquida & $14.980,00$ \\
\hline (-) Custo & $(-7.920,00)$ \\
\hline (=) Lucro Bruto & $7.060,00$ \\
\hline (-) Despesas Operacionais & $(-3.320,00)$ \\
\hline (+) Receitas Financeiras & $1.800,00$ \\
\hline (=) Lucro Líquido & $5.540,00$ \\
\hline
\end{tabular}

Fonte: Própria (2021)

\subsection{FERRAMENTAS FINANCEIRAS}

Segundo os estudos de Assis et al. (2017), uma ferramenta muito difundida entre os empresários é a avaliação de contas a receber e o instrumento menos utilizado é o controle de custo. E quando se fala na utilização das demonstrações contábeis no que se refere à escolha de seus passos no futuro esse manuseio cai ainda mais, o que é realizado através do conhecimento empírico por parte do gestor do negócio, fato que pode trazer consequências ruins à entidade, pois, este conhecimento muitas das vezes não tem base científica, ou seja, sem saber o que de fato está sendo feito para decidir as ações da empresa. 
Ademais, para Martins (2018), o propósito da análise das demonstrações contábeis é expressar a situação das finanças e do patrimônio da entidade e pode ser feita através do Balanço Patrimonial, Demonstração do Resultado do Exercício ou Demonstração de Fluxo de Caixa. E pode ser o começo para traçar um plano futuro para o empreendimento.

Quando se fala de avaliação financeira existem três categorias que dizem respeito à capacidade de liquidez; a estrutura e o capital; e a rentabilidade ou lucratividade. Sendo a de liquidez aquela responsável por analisar se a entidade honrará os pagamentos das dívidas com os terceiros (PEREIRA, 2018).

Com as exibições contábeis é possível acompanhar o desenvolvimento da empresa e avaliar se as decisões tomadas pelos dirigentes estão sendo positivas ou negativas. Portanto, quando um relatório contábil é realizado conforme a legislação é possível examinar as informações geradas e transformá-las em indicadores para serem utilizados nos processos decisórios da entidade (ALBERTON, 2013).

Tendo em vista que as ferramentas financeiras evidenciam se os gestores estão tomando as decisões corretas veremos em seguida alguns desses instrumentos.

\subsubsection{CONTROLE E PLANEJAMENTO FINANCEIRO}

Outra importante ferramenta para o processo decisório da empresa é a projeção financeira que, para Neto et al. (2018), vem sendo bastante utilizada em grandes e pequenas empresas, sendo que, as que usam esse instrumento alcançam melhores resultados. O ponto mais forte quanto ao uso do planejamento financeiro é o de antecipar-se a possíveis inconsistências do mercado ou da companhia para então tomar as devidas atitudes para o desenvolvimento do negócio. Porém o fato de sua estrutura ser voltada para as grandes empresas, a implementação nas micro e pequenas empresas e, por conseguinte, ao microempreendedor individual é relativamente pouco adotada por falta de validação. 
Nesse contexto, Lima e Tomé (2018) também veem o planejamento financeiro como um instrumento de previsão das variáveis do negócio e salientam que ele é um fator fundamental para que as metas sejam alcançadas, por intermédio de um manejo do fluxo de caixa, para que os gestores não cometam erros e sejam auxiliados em suas escolhas. O planejamento financeiro é um aliado no controle das receitas e despesas a curto e longo prazo, tornando as decisões futuras mais fáceis e embasadas na organização de seu orçamento de caixa e suas projeções. Desse modo, Araujo et al. (2015) complementam que devido às mudanças no Brasil quanto à competitividade de mercado, a procura por organização e planejamento define o lugar onde um empreendimento vai estar e para que ocorra da maneira correta, aparece então o planejamento financeiro.

Contudo, Da Costa et al. (2015) faz o alerta que, embora o planejamento financeiro apoie os gestores prevendo momentos ruins, ele pode ser uma faca de dois gumes em que um lado pode trazer sucesso para a entidade, se bem feito, e por outro, pode levar a mesma ao fiasco.

Portanto, ao se planejar o empreendedor se prepara para futuros imprevistos podendo então traçar estratégias com antecedência, permitindo uma continuidade mesmo em tempos não favoráveis.

\subsubsection{FLUXO DE CAIXA}

Segundo Araujo et al. (2015), o fluxo de caixa permite uma melhor gestão da parte financeira da entidade, pois é um instrumento de simples entendimento no auxílio da gestão, visto que, os processos de decisão são embasados nas provisões da receitas que esse dispositivo fornece, facilitando assim, a realização de futuras aplicações.

Segundo Vieira e Batistoti (2015), este aparelho contábil surgiu com o objetivo de promover à entidade o controle das suas finanças, sendo muito significativo para a continuidade da empresa, analisando suas transações financeiras, despesas ou 
investimentos. Sendo necessário para a organização prosseguir com sua finalidade e honrar suas obrigações.

Para Caverzan e Baldissera (2017), com o objetivo de evitar atraso no pagamento de fornecedores e, assim, o acréscimo de juros em cima dessa conta, o fluxo de caixa serve de apoio para que erros como esses não ocorram, pois, quando bem implantado, o gestor tem a sua disposição os dias que o caixa varia positivo ou negativamente, podendo, assim, organizar seus futuros pagamentos.

Martins et al. (2014) complementam que é possível avaliar o potencial da entidade em gerar recurso monetário, em manter em dia suas obrigações e entre outras coisas. Sendo dividida em: atividades operacionais, que são as ações mais importantes que podem alterar a geração do caixa da entidade como o recebimento de cliente ou pagamento de fornecedores; atividades de investimento, sendo classificadas como aquelas em que a geração da disponibilidade é feita em segundo plano ao empreendimento como compra e venda ou aplicações financeiras; e atividades de financiamento, que podem alterar o tamanho dos recursos da empresa, como, por exemplo, financiamentos de longo prazo obtido ou aumento de capital em dinheiro. 
Tabela 3 - Fluxo de caixa

\begin{tabular}{|c|c|c|c|c|}
\hline \multicolumn{5}{|l|}{ FLUXO DE CAIXA } \\
\hline Mês - Setembro / 2021 & DIA 01 & DIA 02 & DIA 03 & DIA 04 \\
\hline ENTRADAS & $3.050,00$ & $3.740,00$ & $3.890,00$ & $5.300,00$ \\
\hline Recebimento de Clientes & $3.120,00$ & $2.930,00$ & $2.890,00$ & $3.900,00$ \\
\hline Outros recebimentos & 930,00 & 810,00 & $1.000,00$ & $1.400,00$ \\
\hline SAÍDAS & $2.000,00$ & $1.520,00$ & $1.750,00$ & $5.700,00$ \\
\hline \begin{tabular}{|l|} 
Pagamento \\
Fornecedores \\
\end{tabular} & e 1.500 & 900,00 & $1.200,00$ & $1.200,00$ \\
\hline Pagamento de Salários & F & - & - & $3.300,00$ \\
\hline Outros pagamentos & 500,00 & 620,00 & 550,00 & $1.200,00$ \\
\hline SALDO OPERACIONAL & $1.050,00$ & $2.220,00$ & $2.140,00$ & $-400,00$ \\
\hline \begin{tabular}{|l} 
SALDO INICIAL \\
ANTERIOR
\end{tabular} & $1.900,00$ & $2.950,00$ & $5.150,00$ & $7.290,00$ \\
\hline SALDO FINAL & $2.950,00$ & $5.150,00$ & $7.290,00$ & $6.890,00$ \\
\hline
\end{tabular}

Fonte: Própria (2021)

Dessa maneira, este instrumento contábil auxilia nas decisões da empresa sobre onde o equivalente de caixa pode ser aplicado, pois, não é bom para o empreendedor ficar com dinheiro "parado".

Na figura abaixo é possível identificar as principais etapas para se obter um fluxo de caixa saudável. 
Figura 1 - Composição do fluxo de caixa

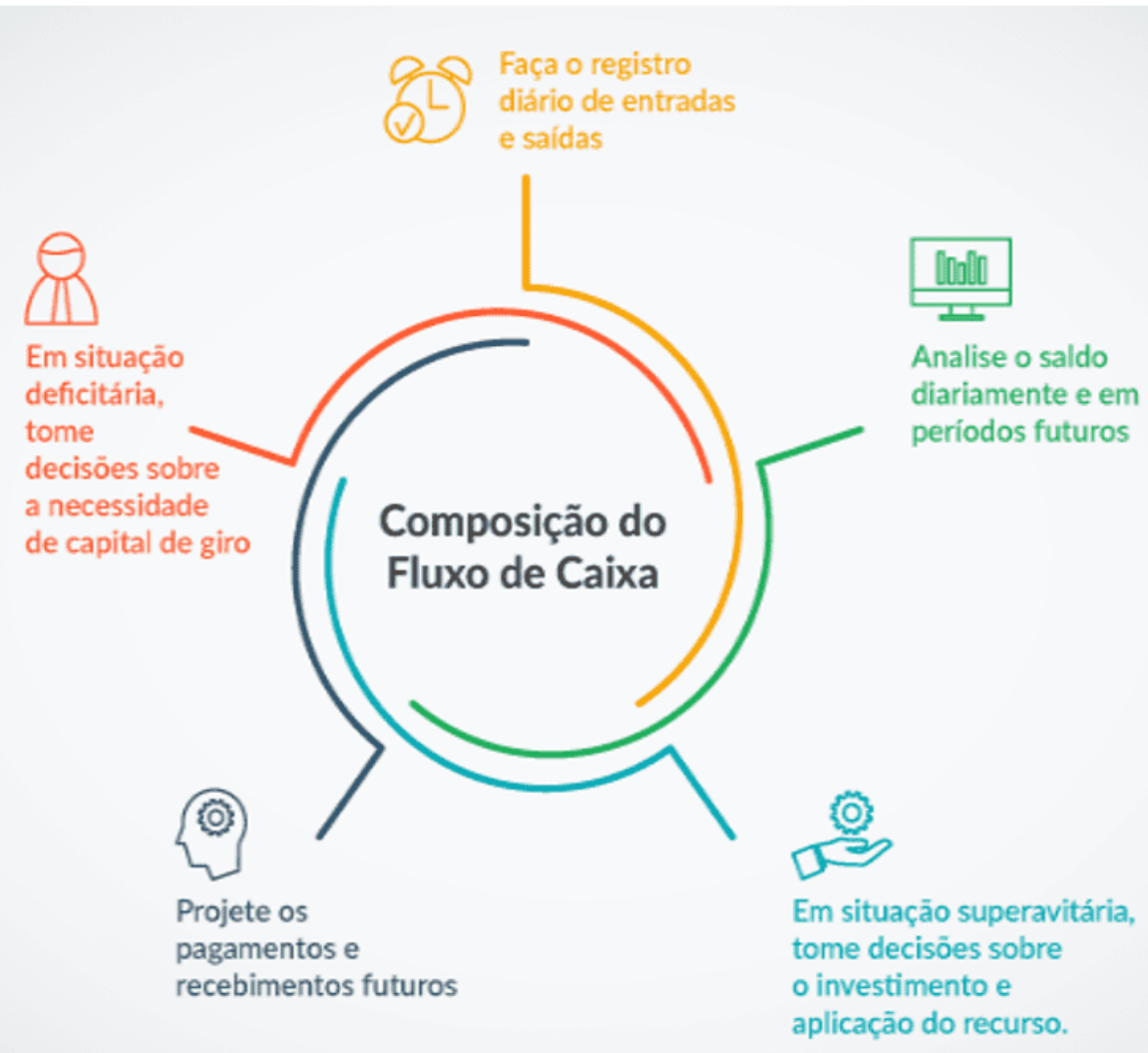

Fonte: SEBRAE (2021)

\subsubsection{CONTROLES BANCÁRIOS}

Para Domingues et al. (2017), ter uma boa gestão significa manter um bom controle dos recursos da empresa, especialmente nas micro e pequenas empresas, com o intuito de haver uma reserva caso aconteça imprevistos financeiros, evitando que a entidade realize empréstimos com juros altos.

Nesse contexto, para o SEBRAE (2018), o crédito para micro e pequeno empresário tem grande requisição, pois, com ela o empreendedor consegue realizar seus objetivos de maior exigibilidade. Geralmente usado nos momentos de baixa disponibilidade no mercado, seja por uma má gestão de recursos ou por uma crise econômica. 
Conforme os estudos de Cassiano (2018), para que o contador saiba o valor concreto da sua situação financeira, ele precisa ter acesso aos seus extratos bancários para, assim, realizar um cruzamento das contas, dos bancos e das finanças e fazer comparações dos saldos presentes nas mesmas. É importante, pois assim o contábil realiza lançamentos ou estornos, caso precise. Tais documentos precisam estar devidamente arquivados cronologicamente para que se evite perda de tempo ou prejuízo financeiro.

Para Crasto (2018), o financiamento é necessário para que o negócio dê um salto e consiga evoluir economicamente, fazendo o seu projeto alcançar metas e perspectivas maiores.

Em suma, ter o controle do banco é fundamental a fim de que o empreendedor consiga futuros investimentos que possam dar ao mesmo capital de giro para manter ou ampliar seu negócio.

\subsubsection{CONTROLE DE RECEITAS}

Segundo o SEBRAE (2016), o microempreendedor individual deve manter o controle de sua receita para que quando for prestar conta de seu faturamento seja mais rápido e fácil, além de que o MEI não pode ultrapassar um determinado limite de faturamento mensal.

Quando falamos de MEI o controle de receita é ainda mais importante, pois, o empreendedor individual tem um limite de receita de $R \$ 81.000,00$ e $R \$ 6.750,00$, devendo prestar conta anualmente até o dia 31 de maio de cada ano (SIMPLES NACIONAL, 2021).

Complementando CHUPEL et al. (2014), o microempreendedor individual deve ter controle de sua receita, pois o mesmo é obrigado a prestar contas mensalmente todo dia 20. Esse relatório mensal facilita a realização da declaração obrigatória no fim do exercício. 
Jeronimo e Dittrich (2018) nos alerta que para evitar surpresas o gerenciamento de estoque é importante, para que o mesmo não perca clientes por falta de material, fato que pode causar danos na receita da empresa, portanto, ter controle de seu estoque ajuda o empresário montar um plano para que seu produto não acabe ou sofra prejuízo de receita por consequência da má gestão de matéria prima.

Portanto, ter controle da receita permite à entidade uma organização de seu faturamento e estoque. E para o microempreendedor é ainda mais importante, pois, o mesmo não pode ultrapassar um certo limite de faturamento.

\subsection{FERRAMENTAS GERENCIAIS}

Segundo Rocha et al. (2018), gerir os recursos é uma das funções da contabilidade para que haja certeza nos processos decisórios da entidade, com ferramentas que podem auxiliar a organização e permitir o controle da mesma. Oferecendo aos gestores instrumentos que possam ajudar a antecipar erros e gerir seu negócio para potencializar suas metas, com a realização de orçamento. Ponto de equilíbrio e fluxo de caixa são algumas dessas ferramentas.

Ademais, Ribeiro e Dos Santos (2018) complementam que com o gerenciamento contábil pode-se analisar, planejar e decidir passos importantes para o progresso do negócio com informações essenciais para a tomada de decisão, fazendo com que o gestor e os usuários internos da entidade tenham noção do que está acontecendo no empreendimento.

Para Corrêa et al. (2017), a possibilidade de gerar informações que podem ajudar os gestores é uma função da contabilidade gerencial, fazendo-se muito necessária para que o empreendimento consiga perpetuar no mercado competitivo, pois, ela oferece mecanismos de avaliação de informações necessárias nos momentos decisórios.

Para Gomes et al. (2021), realizar um orçamento contábil é importante para ter controle da receita e das despesas de um determinado período, para o gestor traçar metas e objetivos, e para o mesmo evitar surpresas negativas no exercício anual. 
Com a intenção do empreendedor ter noção do quanto é preciso para não ter prejuízo e para gerar lucros, a contabilidade oferece ao mesmo uma ferramenta chamada ponto de equilíbrio.

Portanto, as ferramentas gerenciais são ferramentas de controle e organização que oferecem melhor avaliação das informações para tomada de decisão.

\subsubsection{CONTROLE DE CUSTOS E DESPESAS}

O gerenciamento de custo é outra ferramenta que a contabilidade pode oferecer ao empreendedor. Para Barreto e Antonovz (2017), gerir os custos é importante quanto a permanência no mercado, pois, este, dentre outros fatores, influenciam diretamente no sucesso da entidade. Segundo estudos, a ineficaz gestão é apontada como o terceiro maior causador do fracasso dos negócios no Brasil.

Conforme a definição de Pereira e Nunes (2020), despesa é todo consumo direto ou indireto para gerar receita e custo é o gasto para produzir um produto. Dessa maneira, Lopes e Martins (2018) comprovam que controlar o custo auxilia os processos decisórios. Porém, os métodos de custeio são pouco utilizados por desconhecimento próprio do empreendedor ou por não haver um perito em contabilidade para realizar os procedimentos corretamente.

Para Magalhães e Ávila (2018), a origem dessa ferramenta se deu pela contabilidade financeira. Ela oferece condições de gerir e controlar gastos, despesas e custos, potencializando as chances de produção de lucro de uma entidade. Com a gestão de custo, é possível apurar se uma determinada manufatura está gerando lucro ou prejuízo, além de ajudar no processo de definição do preço de venda deste produto.

Conclui-se que o gerenciamento dos gastos influenciam diretamente o lucro da entidade, uma vez que uma má gestão pode corroborar para o fracasso do empreendimento. 


\section{MATERIAIS E MÉTODOS}

Segundo a compreensão de Pereira et al. (2018, p.13), a ciência dar-se-á por meio de experimentação, sendo que, mediante nosso discernimento de tais experiências podemos então compreender e gerar conhecimento. Conhecer é a resolução dos dilemas pessoais e sociais.

A metodologia é muito importante para quem escreve, pois, com ela o autor saberá como sua pesquisa deverá ser feita e para o leitor é importante para que o mesmo saiba o nível de aprofundamento do trabalho.

\subsection{PROCEDIMENTOS METODOLÓGICO}

Para Libório e Terra (2015, p.40), a metodologia é o momento em que o autor da pesquisa irá apresentar ao legente, os processos, os critérios e os recursos que ele precisou para realizar a sua pesquisa. Ela é alterada de acordo com o modelo de estudo, ou seja, cada pesquisa tem suas próprias particularidades, portanto, o método utilizado deve ser feito conforme o tema que o responsável escolheu para sua pesquisa.

Portanto, este presente trabalho se utiliza do método de pesquisa de artigos, livros e revistas com a intenção de responder os questionamentos pertinentes ao propósito do tema ao qual foi escolhido. Fazendo investigação crítica com a intenção de expor uma opinião própria acerca do assunto tratado.

\subsubsection{QUANTO À NATUREZA}

Até a metade do século $\mathrm{XX}$, o método quantitativo tinha uma grande simpatia por parte dos pesquisadores, porém, com o crescimento do estado e consequentemente da população, começaram a ocorrer impasses de cunho sociais levando então o desdobramento e a utilização de métodos qualitativos. Visto que, por meio dessa metodologia, o pesquisador busca não mais quantificar fenômenos, mas sim 
observar seus comportamentos em detrimento aos anseios da sociedade. (GOMES e GOMES, 2019)

Conforme os estudos de Zanella (2013, p.99-100), pode-se afirmar que quando se utiliza o método qualitativo, busca-se expor e comentar sobre determinado assunto sem a intenção de mensurá-lo e sim se aprofundar nas informações preexistentes que o autor irá tratar. Portanto, o método qualitativo é um tipo de pesquisa em que a preocupação do escritor é descrever como um assunto pode ser importante em um determinado momento da sociedade.

Desse modo, o presente artigo utiliza-se do método qualitativo como forma de responder a problemática, embasando-se em dados e informações já produzidas com a intenção de gerar um novo conhecimento a partir de publicações já feitas, permitindo ao pesquisador contribuir à sociedade novas ideias para resolução de um problema social.

\subsubsection{QUANTO AOS FINS}

Para Vergara (2016, p.74) a função de uma pesquisa explicativa é tornar algo compreensivo e de fácil entendimento, portanto, subentende-se que o pesquisador realiza uma avaliação com base em pesquisas descritivas.

$\mathrm{Na}$ compreensão de Zanella (2013, p.34), a busca por catalogar ou encontrar as causas dos acontecimentos de um dilema da sociedade dar-se-á por meio do método explicativo, levando em conta todas as possíveis variáveis que possam influenciar esses fatos sociais.

Levando em conta artigos já publicados o pesquisador responde seus questionamentos através de análises cuidadosas para que não caia em contradição ou erros. Portanto, é importante uma leitura crítica e atenciosa para que sua pesquisa seja satisfatória. 


\subsubsection{QUANTO AOS MEIOS}

O trabalho realizado por meio de estudos já publicados pode ser chamado de pesquisa bibliográfica. Esta promove ao pesquisador fundamentações teóricas para sua própria pesquisa para que, a partir desse aprendizado, ele possa conceber uma nova ideia sobre os materiais já publicados (VERGARA, 2016).

Para Gomes e Gomes (2019, p.13), a pesquisa bibliográfica é um tipo de trabalho em que o pesquisador não aborda o instrumento de pesquisa diretamente, mas sim o analisa por meio de estudos já publicados.

Esta pesquisa busca responder ao problema da falta de informação do microempreendedor e valorizar o profissional contábil por meio de pesquisa bibliográfica com embasamentos bibliográficos, que possam esclarecê-los.

\section{CONSIDERAÇÕES FINAIS}

No decorrer deste trabalho, enfatizamos a importância do contador na supervisão e assessoria ao microempreendedor individual (MEI), a fim de apresentarem as obrigações tributárias em tempo hábil e auxiliarem nos instrumentos de tomada de decisão por meio dos dados divulgados pela contabilidade, coordenados pelo profissional contábil. Possibilitando apontar estratégias que podem ser usadas para o bom gerenciamento e desenvolvimento econômico da empresa.

O presente trabalho teve como objetivo demonstrar a importância dos profissionais da contabilidade para o desenvolvimento do $\mathrm{MEI}$, sendo realizado por meio de métodos qualitativos e pesquisa bibliográfica em livros e artigos, além de publicações em websites voltadas para o assunto.

Por meio da pesquisa sobre a importância dos profissionais da contabilidade para os microempreendedores, emergiu o seguinte questionamento: Como os profissionais da contabilidade podem contribuir para o controle e a organização do MEI? Diante dessa questão, foi visto que o contador é o profissional capacitado para lidar com 
essa problemática, de forma a controlar, organizar, prevenir erros e contribuir para o crescimento do $\mathrm{MEI}$.

Os Microempreendedores, em sua maioria, findam por não saber como remediar os problemas de seus negócios, por haver-Ihes uma lacuna de conhecimento contábil. Nesse sentido, o profissional de contabilidade, através do uso dos conhecimentos técnicos e ferramentas contábeis é capaz de apontar estratégias que auxiliem na tomada de decisão e de realizar a criação de um planejamento financeiro, fiscal e contábil.

Portanto, é visto a importância do auxílio do profissional em contabilidade para o $\mathrm{MEI}$, visando prestar suporte ao microempreendedor, contribuindo para a tomada de decisões e consequente crescimento perante o mercado. Beneficiando não somente o $\mathrm{MEl}$, mas o governo, o mercado de trabalho e a sociedade como um todo.

\section{REFERÊNCIAS}

ALBERTON, L. Análise das demonstrações contábeis. Florianópolis, Departamento de Ciências Contábeis - Universidade Federal de Santa Catarina, 2013. <https://repositorio.ufsc.br/bitstream/handle/123456789/194955/Analise_Demonstrac oes_Contabeis_3ed_MIOLO.pdf?sequence=1>. Acesso em: 22 de Agosto de 2021.

ALENCAR, R. M. B.; DIAS, T. C. Balanço Patrimonial: a importância para a tomada de decisão em micros e pequenas empresas. Revista multidisciplinar e de Psicologia, 2019. Disponível em: <https://doi.org/10.14295/idonline.v13i43.1513>. Acesso em: 25 de agosto de 2021

ARAÚJO, A. et al. A importância da gestão no planejamento do fluxo de caixa para o controle financeiro de micros e pequenas empresas. Revista eletrônica do departamento de ciências contábeis e departamento de atuária e métodos quantitativos da Fea: Redeca, 2015. Disponível em: 
$<$ https://revistas.pucsp.br/index.php/redeca/article/view/28566/20053>. Acesso em: 21 de Agosto de 2021.

ARAÚJO, F. M. de; DOS ANJOS, M. A. D. A importância da contabilidade para o Microempreendedor Individual (Mei). Fundação Carmelitana Mário Palmério FUCAMP, 2019 Disponível em: $<$ http://repositorio.fucamp.com.br/jspui/handle/FUCAMP/489>. Acesso em: 26 de Agosto de 2021.

ASSIS, A. et al. Como são utilizadas as ferramentas gerenciais em micro e pequenas empresas de agroturismo no município de venda nova do imigranteEs. Anais do Seminário Científico do Unifacig, 2017. Disponível em: $<$ http://www.pensaracademico.facig.edu.br/index.php/semiariocientifico/article/view/4 85/410 >. Acesso em: 24 de Agosto de 2021.

AZEVEDO, D. Revisão de literatura, referencial teórico, fundamentação teórica e framework conceitual em pesquisa: diferenças e propósitos. Workpaper, 2016. Disponível em: <https://unisinos.academia.edu/DeboraAzevedo/Papers>. Acesso em: 30 de Agosto de 2021

BARRETO, A. F.; ANTONOVZ, T. A influência da falta de gestão de custos no encerramento das empresas no Brasil. Revista Científica Hermes, 2017. Disponível em: $<$ https://www.redalyc.org/jatsRepo/4776/477653290002/477653290002.pdf>. Acesso em: 24 de Agosto de 2021.

CASSIANO, V. M. A importância do controle interno na gestão das pequenas empresas: estudo de caso realizado em uma empresa de pequeno porte. Universidade Tecnológica Federal do Paraná: Pato Branco-PR, 2018. Disponível em:

$<$ http://repositorio.utfpr.edu.br/jspui/bitstream/1/14218/2/PB_COCTB_2018_2_21.pdf >. Acesso em: 28 de Agosto de 2021. 
CAVERZAN, G. M.; BALDISSERA, A. L. Um estudo da aplicação do fluxo de caixa em uma empresa transportadora do estado de Santa Catarina. Revista Unoesc \& Ciência, ACSA Joaçaba, 2017. Disponível em: $<$ https://core.ac.uk/download/pdf/235125136.pdf>. Acesso em: 21 de Agosto de 2021.

CHUPEL, J. F. et al. A importância da contabilidade para microempreendedor individual. Revista Eletrônica da Faculdade de Alta Floresta, 2014. Disponível em $<$ http://faflor.com.br/revistas/refaf/index.php/refaf/article/view/161>. Acesso em: 26 de Agosto de 2021

CORRÊA, C. da S. et al. O desempenho organizacional por meio da contabilidade gerencial quanto a utilização de ferramentas de gestão. Revista Disciplinarum Sciential/ Sociais Aplicadas, 2017. Disponível em: $<$ https://periodicos.ufn.edu.br/index.php/disciplinarumSA/article/view/2349/2066>. Acesso em: 24 de Agosto de 2021.

COSTA, M. L.; FEITOSA FILHO, R. I. A importância da contabilidade no processo de desenvolvimento do Microempreendedor Individual (MEI). Revista Brasileira de Administração Científica, 2019. Disponível em: <http://doi.org/10.6008/CBPC2179-684X.2019.002.0011>. Acesso em: 26 de Agosto de 2021

CostA, R. A. T. et al. A análise da demonstração do resultado do exercício: como ferramenta de gestão para o administrador. Revista de empreendedorismo e gestão de micro e pequenas empresas, 2016. Disponível em: $<$ https://www.revistas.editoraenterprising.net/index.php/regmpe/article/view/72/49>. Acesso em: 28 de Agosto de 2021.

CRASTO, D. de L. Financiamento das empresas e os determinantes da concessão de crédito bancário. Universidade do Minho: Escola de Economia e Gestão, 2018. Disponível em: <http://hdl.handle.net/1822/59445>. Acesso em: 21 de Agosto de 2021 
DA COSTA, L. L. et al. Planejamento financeiro para micro e pequenas optantes pelo Simples Nacional. Revista EVS - Revista Ambientais e Saúde, 2015. Disponível em: <http://seer.pucgoias.edu.br/index.php/estudos/article/view/4014/2318>. Acesso em: 21 de Agosto de 2021.

DA SILVA, R. R. O Microempreendedor Individual Mei - Uma abordagem sobre a efetividade das vantagens, benefícios e desafios gerados ao novo empreendedor. Fundação Universidade Federal de Rondônia, Cacoal - RO, 2014. Disponível em: <https://core.ac.uk/download/pdf/294852743.pdf>. Acesso em: 26 de Agosto de 2021

DO CARMO, V. J. D. A análise do balanço e da DRE: um estudo de caso da empresa Energisa Mato. Universidade Federal do Mato Grosso: Cuiabá - MT, 2017. Disponível em: <http://bdm.ufmt.br/handle/1/235>. Acesso em: 25 de Agosto de 2021.

DOMINGUES, O. G. D. et al. Gestão de capital de giro e formação do preço de venda praticado pelas micro e pequenas empresas. Revista Ambiente Contábil, UFRN: Natal - $\quad$ RN, $2017 . \quad$ Disponível em: $<$ https://ojs.ccsa.ufrn.br/index.php/contabil/article/view/748>. Acesso em: 23 de Agosto de 2021.

FRANÇA, A. A. de; ANDRADE, E. S. A formação de preço de venda no âmbito do Microempreendedor Individual: um estudo nas empresas do ramo varejista de artigos do vestuário de Iguatu - Ceará. Revista Livre de Sustentabilidade e Empreendedorismo, 2020.

Disponível

em: $<$ https://www.relise.eco.br/index.php/relise/article/view/278/394>. Acesso em: 30 de Agosto de 2021.

GOMES, A. J. de A. et al. Contabilidade gerencial: a importância das ferramentas gerenciais contábeis nas microcompanhias. Brazilian Journal of Development, 2021. Disponível em: 
$<$ https://www.brazilianjournals.com/index.php/BRJD/article/view/31374/pdf>. Acesso em: 24 de Agosto de 2021.

GOMES, A. S.; GOMES, C. R. de A. Classificação dos tipos de pesquisa em informática na educação. Capítulo 4. 2019. Disponível em: <https://metodologia.ceie-br.org/wp-content/uploads/2019/06/livro1_cap4.pdf>. Acesso em: 20 de Agosto de 2021.

GONÇALVES, A. C. P. et al. Demonstração do resultado do exercício e demonstração do fluxo de caixa: um estudo quanto a acessibilidade em empresas de pequeno porte. Revista de Ciências Contábeis: UFMT, 2019. Disponível em: $<$ https://periodicoscientificos.ufmt.bt/ojs/index.php/rcic/article/view/9842>. Acesso em: 21 de Agosto de 2021.

JERONIMO, G. P.; DITTRICH, M. T. A importância do controle de estoques em uma empresa de material de construção. Faculdade Capivari: FUCAP, 2018. Disponível em: $<$ https://www.fucap.edu.br/dashboard/biblioteca_repositorio/2d87741eaae07c508c11 3ca7e8a763f6.pdf>. Acesso em: 22 de Agosto de 2021.

LAMES, E. R. de. Conceitos de contabilidade e suas relações com a estrutura conceitual básica, com a formação docente e rendimento discente. Universidade Federal de Uberlândia, Uberlândia, 2019. Disponível em: <http://dx.doi.org/10.14393/ufu.te.2019.2448 >. Acesso em: 26 de agosto de 2021.

LIBÓRIO, D.; TERRA, L. Metodologia Científica. Editora Laureate International Universities, 2015. Disponível em: <https://www.academia.edu/download/53349152/metodologia_cientifica_unidade_2. pdf $>$. Acesso em: 20 de Agosto de 2021.

LIMA, V. R.; TOMÉ, A. S. A importância da adoção de um planejamento financeiro para a gestão e crescimento das pequenas empresas. Revista 
Eletrônica Gestão e Serviços, 2018. Disponível em: $<$ https://pdfs.semanticscholar.org/2928/c75389c9ed62274fd267bba8e9d7d2cfb167.p df>. Acesso em: 21 de Agosto de 2021.

LOPES, A. C. V.; MARTINS, L. A. Gestão de custo nas micro e pequenas indústrias do setor de confecções da cidade de Dourados/MS. Anais do congresso brasileiro de custo: ABC, 2018. Disponível em: $<$ https://anaiscbc.emnuvens.com.br/anais/article/view/4588>. Acesso em: 24 de Agosto de 2021.

MAGALHÃES, A. P.; ÁVILA, E. M. de. Gestão de custo: a importância do controle de custos em uma empresa prestadora de serviço. Faculdade Doctum De João Monlevade, 2018. Disponível em: <http://hdl.handle.net/123456789/3101>. Acesso em: 24 de Agosto de 2021.

MARTINS, E. et al. Análise didática das demonstrações contábeis. São Paulo: Atlas, 2014.

MARTINS, R. B. Ferramentas de contabilidade gerencial adotadas por micro e pequenas empresas. Universidade Federal da Paraíba, 2018. Disponível em: <https://repositorio.ufpb.br/jspui/handle/123456789/11892>. Acesso em: 21 de Agosto de 2021.

MESQUITA, K. M. de. O Microempreendedor Individual e sua relação com os escritórios de contabilidade. Universidade do Extremo Sul Catarinense, 2016. Disponível em: <http://repositorio.unesc.net/handle/1/4436>. Acesso em: 26 de Agosto de 2021.

NASCIMENTO, J. D. B. Do. Análise de balanço patrimonial e demonstração do exercício como ferramenta para tomada de decisão e previsão de solvência. Universidade Federal de Alagoas, 2015. Disponível em: $<$ https://www.repositorio.ufal.br/jspui/handle/riufal/3764>. Acesso em: 28 de Agosto de 2021. 
NETO, J. V. et al. Desafios da implantação do planejamento estratégico pela micro e pequena empresa. Revista Espacios, 2018. Disponível em: $<$ https://revistaespacios.com/a18v39n33/a18v39n33p09.pdf>. Acesso: 21 de Agosto de 2021.

PEREIRA, A. G. Análise das demonstrações contábeis. Universidade Federal da Bahia, 2018. Disponível em: <http://repositorio.ufba.br/ri/handle/ri/30845>. Acesso em: 22 de Agosto de 2021.

PEREIRA, A. S. et al. Metodologia da pesquisa científica. Universidade Federal de Santa Maria: RS, 2018. Disponível em: <http://reposito.ufsm.br/handle/1/15824>. Acesso em: 20 de Agosto de 2021.

PEREIRA, E. S.; NUNES, I. D. Formação do preço de venda para o microempreendedor. Universidade de Taubaté: São Paulo, 2020. Disponível em: $<$ http://repositorio.unitau.br/jspui/handle/20.500.11874/3897>. Acesso em: 24 de Agosto de 2021.

RIBEIRO, A. M. R.; DOS SANTOS, L. N. Contabilidade gerencial: a contabilidade como ferramenta gerencial para tomada de decisões de micro e pequenas empresas. Faculdade Doctum de João Monlevade, 2018. Disponível em: <http://hdl.handle.net/123456789/3091 >. Acesso em: 24 de Agosto de 2021.

RIBEIRO, O. M. Contabilidade básica fácil. 29ª ed. Editora Saraiva, 2013.

ROCHA, J. F. de A. et al. A contabilidade gerencial no processo de tomada de decisão e o conhecimento das empresas sobre sua importância. Revista Fatec Zona Sul, v.5, n.2 p.66-75, 2018. Disponível em: <http://revistarefas.com.br/index.php/RevFATECZS/article/view/231/192>. Acesso em: 24 de Agosto de 2021.

RODRIGUES, C. M. Manual de contabilidade básica aplicada à gestão. Faculdade de Tecnologia de Curitiba: PR, 2021. 
SEBRAE. Dicas financeiras para o negócio do MEI. 2018. Disponível em <https://www.sebrae.com.br/sites/PortalSebrae/ufs/ap/artigos/dicas-financeiras-parao-negocio-do-mei,2e8304f99f103610VgnVCM1000004c00210aRCRD>. Acesso em: 23 de agosto de 2021.

SEBRAE. Série MEI: passo a passo para elaboração do relatório mensal. 2016 <https://www.sebrae.com.br/sites/PortalSebrae/ufs/ms/artigos/serie-mei-passo-apasso-para-elaboracao-do-relatoriomensal,a0a12bb750c04510VgnVCM1000004c00210aRCRD>. Acesso em: 21 de Agosto de 2021.

SEBRAE. Tudo o que você precisa saber sobre o MEI. 2021. Disponível em <https://www.sebrae.com.br/sites/PortalSebrae/artigos/tudo-o-que-voce-precisasaber-sobre-o-mei,caa7d72060589710VgnVCM100000d701210aRCRD>. Acesso em: 30 de Agosto de 2021.

SIMPLES NACIONAL. Perguntas e respostas: Simples Nacional. SecretariaExecutiva do Comitê Gestor do Simples Nacional, 2021. Disponível em <http://www8.receita.fazenda.gov.br/SimplesNacional/Perguntas/Perguntas.aspx>. Acesso em: 30 de agosto de 2021.

VERGARA, S. C. Projetos e relatórios de pesquisa em administração. 16 ed., São Paulo: Atlas, 2016.

VIEIRA, E. T. V.; BATISTOTI, J. V. da C. A demonstração do fluxo de caixa como instrumento de gerenciamento e controle financeiro para as micro e pequenas empresas. Revista de Micro e Pequenas Empresas e Empreendedorismo, 2015. Disponível em: <https://dialnet.unirioja.es/servlet/articulo?codigo=5850651>. Acesso em: $21 / 08 / 2021$.

ZANELLA, L. C. H. Metodologia de pesquisa. $2^{\underline{a}}$ ed. Florianópolis: Departamento de Ciências da Administração, 2013. 
Enviado: Outubro, 2021.

Aprovado: Novembro, 2021. 